\title{
Liquefaction Assessment in Golem Area, Albania, by Means of In-situ Tests
}

\author{
Shpresa Gashi and Neritan Shkodrani \\ Department of Civil Engineering, Faculty of Civil Engineering, Polytechnic of Tirana, Tiran 1000, Albania
}

\begin{abstract}
The liquefaction is a very significant phenomenon in clayey silty soils, silty sands and also sands. The high potential of liquefaction is generally recognized when these types of soils are laid under the hydrostatic water table. Low plasticity silts, silty sands and sands are found as recent alluvial deposits in the western coastal part of Albania, especially in the sandy beaches of Adriatic Sea near Durres City. The aim of this study is to evaluate the soil liquefaction potential in the area of Golem. Ten CPTUs (cone penetration test with pore pressure measurements) are carried out for the site investigation of soils. In this paper, results of the CPTU based liquefaction analysis are presented. The data of two CPTUs (10 in total) are analyzed and factor of safety was found by considering different levels of hazard and ground water. The results of liquefaction potential analysis show that the soils in the area of Golem have a high risk of liquefaction.
\end{abstract}

Key words: Cone penetration test, liquefaction potential, cyclic resistance ratio, cyclic stress ratio, safety factor.

\section{Introduction}

Liquefaction is a phenomenon in which the strength and stiffness of a soil is reduced by earthquake shaking or other dynamic loading. Liquefaction happens when there is a loose of strength in saturated and cohesion-less soils because of increased pore water pressures and hence reduced affective stresses due to dynamic loading. Liquefaction has been responsible for tremendous amount of damage in historical earthquake around the world. This phenomenon has been studied by several authors as Robertson and Wride [1], Idriss and Boulanger [2], Moss et al. [3] and Juang [4]. In Albanian, this phenomenon is studied for the city of Vlora and Durres for the first time by Koçiaj et al. [5]. Correlations based on in-situ tests are widely used in engineering practice to estimate the potential of liquefaction triggering. This paper summarizes evaluation of liquefaction according to the deterministic approach. The aim of this paper is to

Corresponding author: Shpresa Gashi, M.Sc., research fields: soil mechanics and foundation engineering. E-mail: gashi84_shpresa@yahoo.com. evaluate the liquefaction potential in this area for the first time. The type of soils met, which are silty sands and sandy silt, clay and silty clay, are suspected to liquefy. The area under study is situated at Golem Municipality of Kavaja County, at the central Albanian coast, in Tirana Prefecture. This is an overpopulated area and many buildings are constructed very close to the sea coast line. Generally, the buildings have shallow foundations embedded to the upper soil layers, usually at a depth of $2.0 \mathrm{~m}$ to $4.0 \mathrm{~m}$. In order to conduct this research study, 10 CPTU tests are carried out by In Situ Balkans Company in different locations across the coastal line, mentioned below as boreholes, BH-i. From 10 Piezocone tests, six of them are considered valid, which are BH-1, 2, 3, 4, 5 and 8 shown in Fig. 1. The penetration depth varies from $8.0 \mathrm{~m}$ to $20.0 \mathrm{~m}$ and the soil profiles of two boreholes taken into consideration in this study are given in Fig. 2. The soil behavior type index $I_{c}$ is used to identify the layers with high potential of liquefaction from the CPTU test data.

The main types of soils met in this area are sands and silty sand, silty sands and sandy silt, clay and silty clay. From 10 CPTU tests carried out, only two of them 


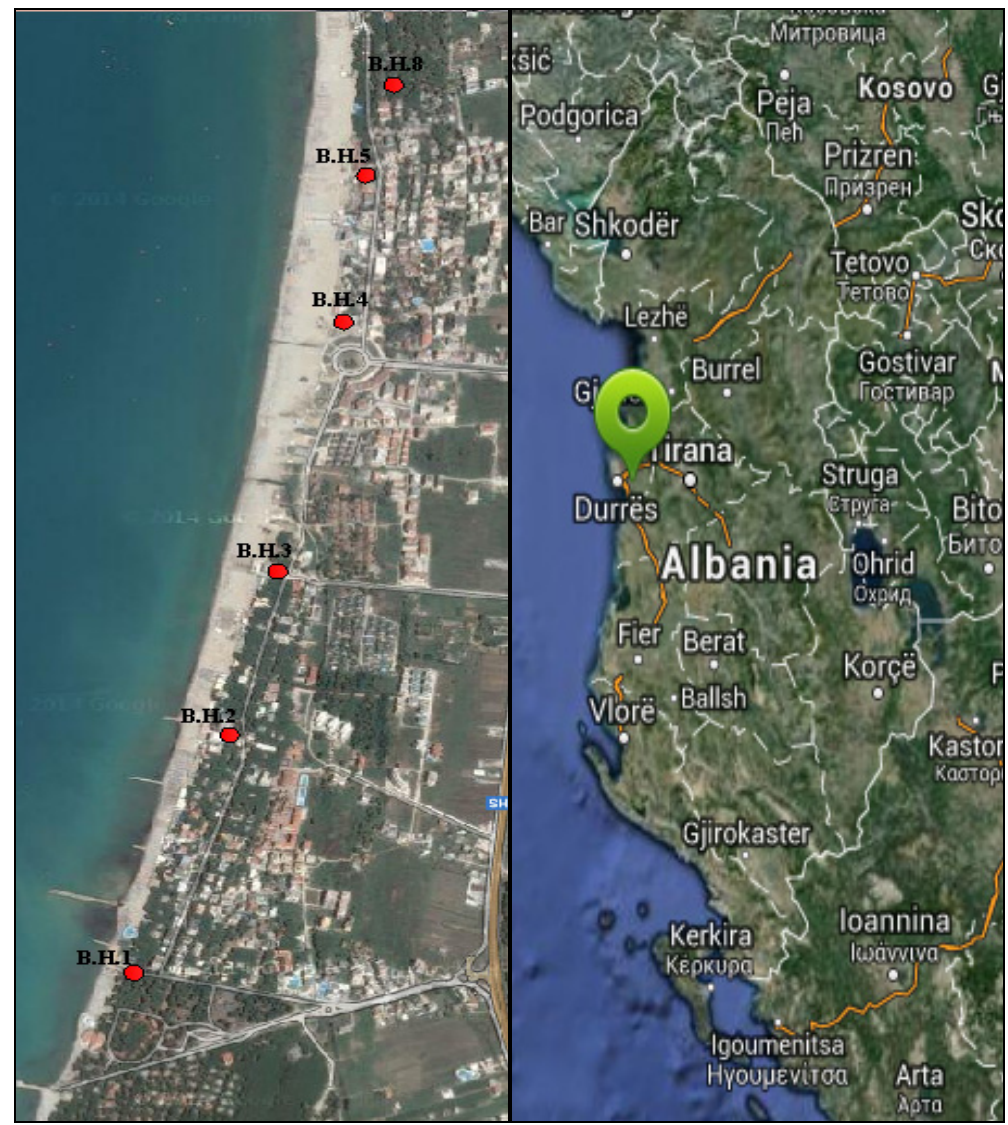

Fig. 1 Geographic location of the study area.

BH-1

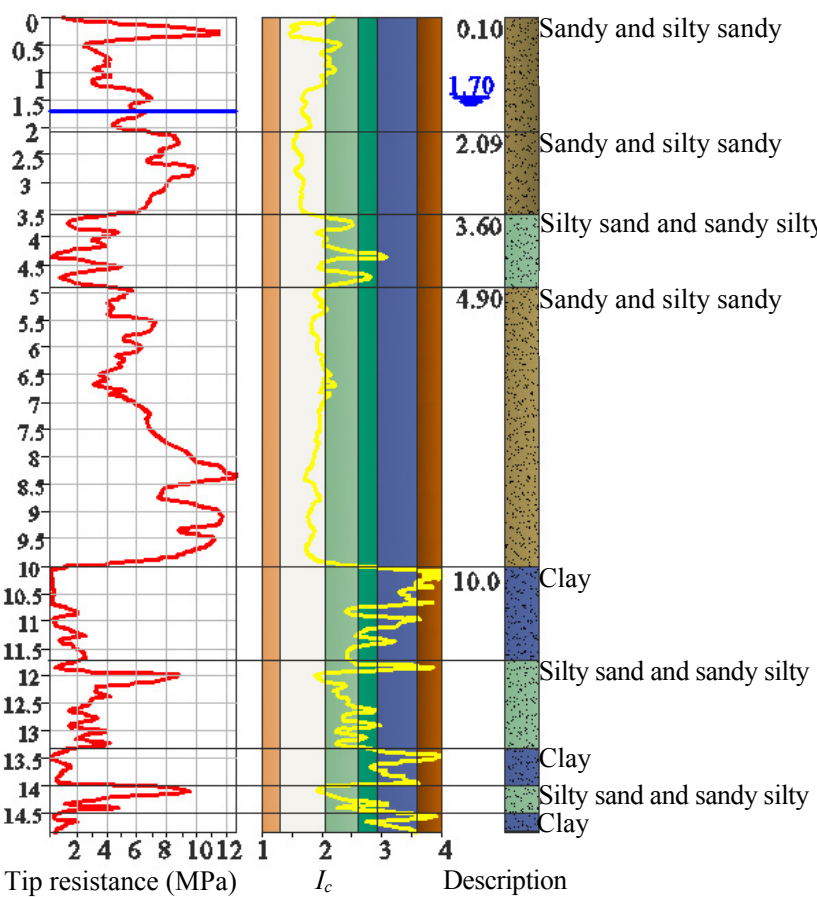

(a)
BH-8

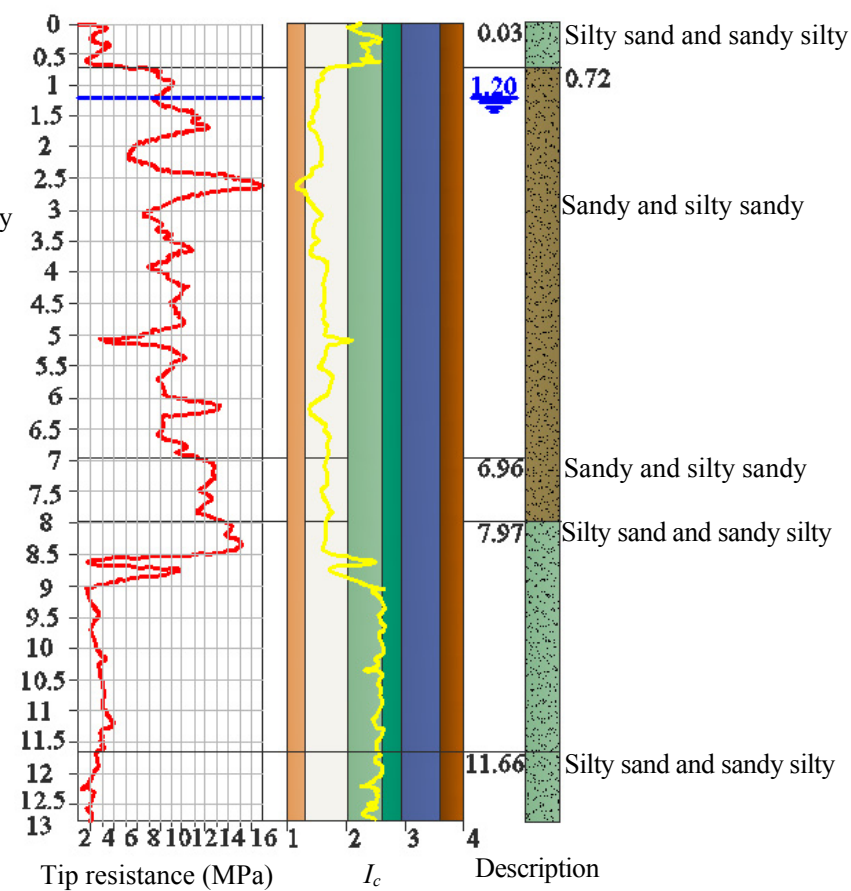

(b)

Fig. 2 Soil profiles for: (a) Borehole BH-1; (b) Borehole BH-8. 
are taken into consideration, $\mathrm{BH}-1, \mathrm{BH}-8$. During the liquefaction analysis, natural groundwater level is at a depth of $1.7 \mathrm{~m}$ for BH-1 and $1.2 \mathrm{~m}$ for BH-8, but FS (factor of safety) is evaluated also for two other scenarios related to the groundwater level. The second groundwater level is supposed at the ground surface, while the third level $1.0 \mathrm{~m}$ above the ground surface, considering the last one as an average flood scenario. From the seismic point of view, this area is located in the Periadriatic Depression, denoted as PL (Periadriatic Lowland)-zone, strongly affected by post-Pliocene compression movements, in direct convergence with Adria microplate. It is characterized by a high seismic activity and, according to the seismic hazard map of Albania, two levels of hazards are considered. The first level of hazard represents an earthquake with $50 \%$ probability of exceedance during the life-span of the structure (considered as 50 years) or a $P G A$ (peak ground acceleration) equal to $0.13 \mathrm{~g}$, and the second level of hazard represents an earthquake with $10 \%$ probability of exceedance in 50 years, or a $P G A=0.273 \mathrm{~g}$ [6]. According to the Albanian earthquakes catalogue, the expected earthquake surface wave magnitudes $(M s)$ of the considered area vary from 4.5 6.6 [7]. The highest magnitude is $M s=6.6$ (year 346 and in the region with coordinates: $\left.41.30^{\circ} \mathrm{N} ; 19.30^{\circ} \mathrm{E}\right)$.

\section{Methodology}

The "simplified procedure" originally developed by Seed and Idriss [8] and later by other authors as Robertson [9] is used to evaluate liquefaction potential. This procedure essentially compares the $C R R$ (cyclic resistance ratio) at a given depth with the earthquake-induced CSR (cyclic stress ratio) at the depth from specified design earthquake.

\subsection{Evaluation of CRR}

The average uniform $C S R$ within a liquefiable layer is given by Seed and Idriss [8]:

$$
\operatorname{CSR}=\frac{\tau_{c y c}}{\sigma_{v 0}^{\prime}}=0.65 \cdot\left(\frac{a_{\max }}{g}\right) \cdot\left(\frac{\sigma_{v 0}}{\sigma_{v 0}^{\prime}}\right) \cdot r_{d}
$$

where:

$\tau_{c y c}=$ cyclic shear stress;

$a_{\max }=$ peak horizontal ground acceleration generated by the earthquake;

$\mathrm{g}=$ acceleration of gravity;

$\sigma_{v 0}=$ initial vertical total stress;

$\sigma_{\nu 0}^{\prime}=$ initial vertical effective stress;

$r_{d}=$ stress reduction factor.

Liao and Whitman [10] proposed the calculation of $r_{d}$ as a function only of the soil depth as follows:

$$
\begin{gathered}
r_{d}=1.0-0.00765 \cdot z \quad \text { if } z<9.15 \mathrm{~m} \\
r_{d}=1.174-0.0267 \cdot z \quad \text { if } z \geq 9.15 \mathrm{~m}
\end{gathered}
$$

where, $z$ is the depth in meters.

\subsection{Evaluation of $C R R$}

The CSR is evaluated using the CPT (cone penetration test), which is considered to be a reliable device for soil investigation by today's standards, providing important information on soil types and geotechnical parameters.

For the cyclic resistance ratio of clean sands and a magnitude of $7.5\left(C R R_{7.5}\right)$, Robertson and Wride [1] and Roberson [11, 12] have proposed the following equations:

$$
\begin{aligned}
C R R_{c}= & 0.833 \cdot\left[\left(q_{c 1, N}\right)_{c s} / 1,000\right]+0.05 \\
& \text { for }\left(q_{c 1, N}\right)_{C S}<50 \\
C R R_{c}= & 93 \cdot\left[\left(q_{c 1, N}\right)_{c s} / 1,000\right]^{3}+0.08 \\
& \text { for } 50 \leq\left(q_{c 1, N}\right)_{C S} \leq 160
\end{aligned}
$$

where:

$\left(q_{c l, N}\right)_{c s}$ is the normalized cone penetration resistance, corrected for the fine content influence:

$$
\left(q_{c 1, N}\right)_{c s}=K_{c} \cdot\left(q_{c 1, N}\right)
$$

$K_{c}$ is a correction factor that is a function of grain characteristics (combined influence of fines content and plasticity) of the soil:

$$
K_{c}=1 \text { for } I_{c} \leq 1
$$




$$
\begin{gathered}
K_{c}=-0.403 I_{c}^{4}+5.581 I_{c}^{3}-21.631 I_{c}^{2}+33.75 I_{c}-17.88 \\
\text { for } I_{c} \geqslant 1.64
\end{gathered}
$$

Robertson and Wride [1] suggested estimating the grain characteristics using the soil behaviour chart by Robertson [13] and the soil behaviour type index $I_{c}$ :

$$
I_{c}=\left[(3.47-\log Q)^{2}+(1.22+\log F)^{2}\right]^{0.5}
$$

and

$$
\begin{aligned}
& Q=\frac{q_{c}-\sigma_{v}}{P_{a}} \cdot\left(\frac{P_{a}}{\sigma_{v}^{\prime}}\right)^{n} \\
& F_{R}=100 \cdot \frac{f_{s}}{\left(q_{c}-\sigma_{v}\right)}
\end{aligned}
$$

where:

$Q$ is the normalized cone penetration resistance;

$F_{R}=$ is normalized friction ratio;

$\sigma_{v}$ and $\sigma_{v}^{\prime}$ are the initial total and effective overburden stresses, respectively;

$P_{a}$ is the atmospheric pressure;

$q_{c}$ is the measured tip resistance;

$f_{s}$ is the CPT sleeve friction resistance;

$n$ is the stress exponent.

The stress exponent " $n$ " varies according to the soil type. The typical value of " $n$ " is 0.5 for clean sands and 1 for clays. For silts and silty sand, an intermediate value between 0.5 and 1 is appropriate.

The normalized cone penetration resistance " $Q$ " is calculated first, assuming that $n=1$. The soil behaviour type index, $I_{c}$ calculated for $n=1$, is then introduced in the next step of calculation of " $n$ " value:

$$
n=0.381 \cdot\left(I_{c}\right)+0.05 \cdot\left(\frac{\sigma_{v}^{\prime}}{P_{a}}\right)-0.15
$$

Then, a new " $Q$ " value is calculated with the last value of " $n$ ": an iteration procedure through " $I_{c}$ " and " $Q$ " proposed by Robertson [13] is used to evaluate " $n$ " until the difference between the last values of " $n$ " is less than 0.01 .

The last found value of " $n$ " allows to calculate $q_{\mathrm{cl}, N}$, in Eq. (6) which is the normalized cone penetration resistance defined as follow:

$$
q_{c 1, N}=\frac{q_{c}-\sigma_{v}}{P_{a 1}} \cdot\left(\frac{P_{a}}{\sigma_{v}^{\prime}}\right)^{n}
$$

The final value of " $I_{c}$ " is used to compute the value of $K_{c}$ given in Eqs. (7) and (8).

\subsection{Magnitude Scaling Factor}

The MSF (magnitude scaling factor) has been used to adjust the induced $C S R$ during an earthquake of magnitude $M$ by using the $C S R$ for an earthquake magnitude, $M_{w}=7.5$. The $M S F$ is thus defined as:

$$
M S F=C S R_{M} / C S R_{M=7.5}
$$

Thus, $M S F$ provides an approximate representation of the effects of shaking duration or equivalent number of stress cycles. Values of magnitude scaling factors are derived by combining: (1) correlation of the number of equivalent uniform cycles versus earthquake magnitude; (2) laboratory-based relationships between the cyclic stress ratios required to cause liquefaction and the number of uniform stress cycles. The value of scaling factor, $M S F$, is proposed by various researchers (reproduced from Youd and Nobel [14]).

In this paper, $M S F$ proposed by Idriss [15] is used to evaluate the liquefaction potential:

$$
M S F=10^{2.24} / M^{2.56}
$$

\subsection{Evaluating Factor of Safety}

When the values of $C R R$ and $C S R$ are established for a stratum at a given depth, $F S$ against liquefaction should be calculated. The FS against liquefaction is defined as [16]:

$$
F S=C R R / C S R
$$

Liquefaction is accepted to occur when $F S$ is less than 1 or 1.2 .

\section{Results and Discussions}

The liquefaction potential evaluation is done by using the values of $F S$ which is given as the ratio between $C R R$ and $C S R$. According to the values of the $F S$, it is accepted that liquefaction has high susceptibly to happen for $F S<1$, medium susceptibly for the interval $1.0<F S<1.25$ and low susceptibly for $F S>1.25$. FS is evaluated for two different levels of seismic hazard: 1 st level with a maximum acceleration 


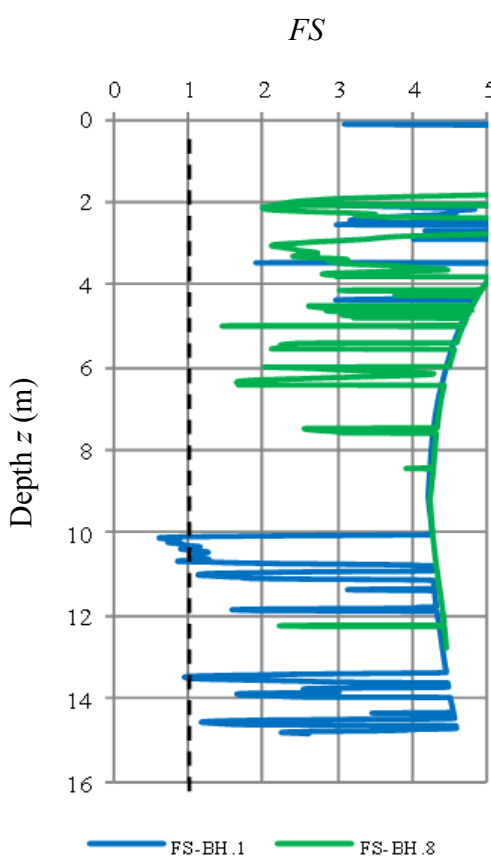

(a)

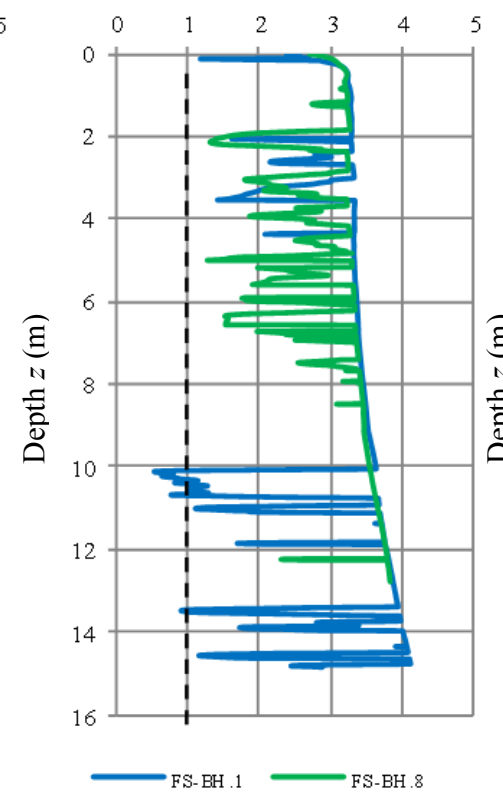

(b)
FS

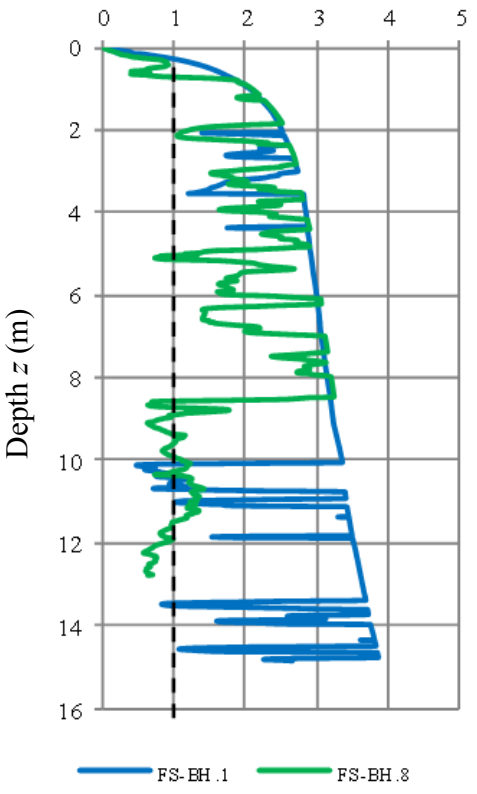

(c)

Fig. 3 FS for BH-1 and BH-8, $a_{\max }=0.137 \mathrm{~g}, M=6.6$, for three different scenarios of G.W.L (ground water level): (a) $-1.2 /-1.7 \mathrm{~m}$ below the ground surface; (b) $0.0 \mathrm{~m}$ at ground surface; (c) $+1.0 \mathrm{~m}$ above the ground surface.

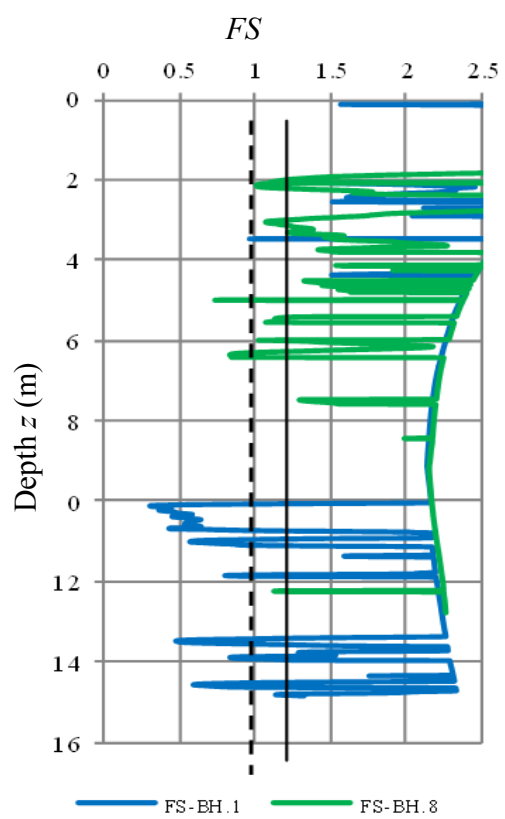

(a)

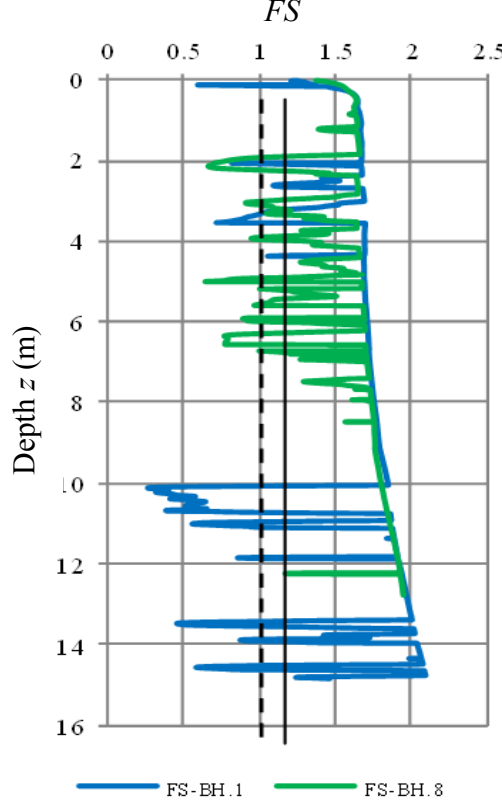

(b)

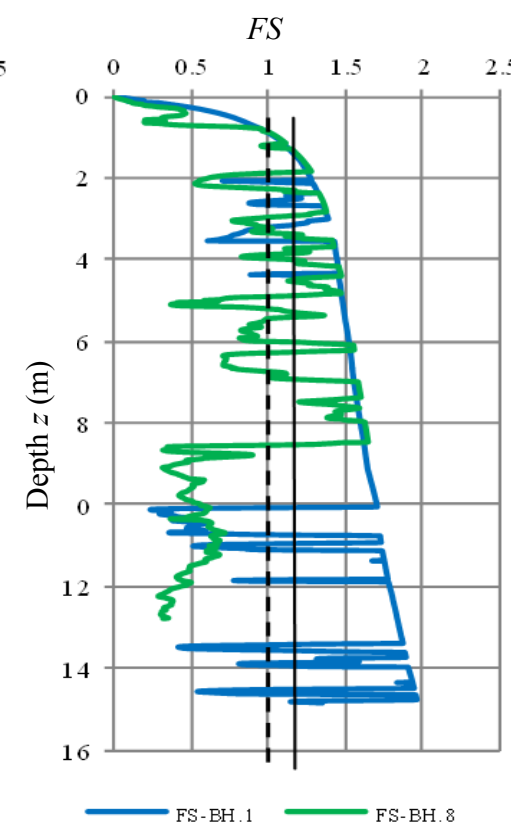

(c)

Fig. $4 F S$ for BH-1 and BH-8, $a_{\max }=0.237 \mathrm{~g}, M=6.6$, for three different scenarios of G.W.L: (a) $-1.2 /-1.7 \mathrm{~m}$ below the ground surface; (b) $0.0 \mathrm{~m}$ at ground surface; (c) $+1.0 \mathrm{~m}$ above the ground surface.

equal to $0.137 \mathrm{~g}$ (72 years return period); and for $2 \mathrm{nd}$ level with a maximum acceleration equal to $0.273 \mathrm{~g}$ (475 years return period) or a maximum magnitude $M$
$=6.6$. The above-mentioned data are taken by Aliaj et al. [2]. FS is evaluated for three different scenarios related to the water levels. The first one is the natural 
groundwater level, which is found at $-1.70 \mathrm{~m}$ and $-1.20 \mathrm{~m}$ below the ground surface for $\mathrm{BH}-1$ and $\mathrm{BH}-8$, respectively. The second one is considered at $\pm 0.0 \mathrm{~m}$ or at the ground surface (considered as the water level during the seismic shakes) and the third one is accepted at $+1.0 \mathrm{~m}$ above the ground surface. It was observed from the considered cases analyzed above that, for the first hazard level, liquefaction has low susceptibility to occur. This phenomenon occurs for the two boreholes BH-1 and BH-8 (Fig. 3): for BH-1 (Figs. 3a and $3 \mathrm{~b}$ ), there are two intervals of depth, where $F S<1$. At a depth interval of $2.0 \sim 4.0 \mathrm{~m}$ and $10.0 \sim 14.5 \mathrm{~m}$ for all considered scenarios related to the water levels: for BH-8 (Fig. 3c), $F S<1$ is at the depth interval of 8.5-13.0 m, but only for the worse scenarios related to the water levels, when G.W.L is accepted to be $+1.0 \mathrm{~m}$ above the ground surface. For the second hazard level, Fig. 4 indicates that generally the liquefaction has medium susceptibility to occur (see values between the interrupted and continues lines).The liquefiable soil layers are found at both boreholes BH-1 and BH-8 and for all considered scenarios related to the water levels (as mentioned above): for BH-1 at a depth interval of $2.0 \sim 4.5 \mathrm{~m}$ and in the interval $10.0 \sim 14.5 \mathrm{~m}$, there is high susceptibility to liquefaction where G.W.L is $-1.7 \mathrm{~m}$ below the ground surface and it is increased at the case where G.W.L is accepted to be $+1.0 \mathrm{~m}$ above the surface; for BH-8 at the depth interval of $0.0 \sim 7.0 \mathrm{~m}$ and $8.5 \sim 12.5 \mathrm{~m}$.

\section{Conclusions}

From the analyses, it is shown that FS decreases with the increase of the ground water level. The worst situation, related to the liquefaction, is found when the ground water level is supposed to be $+1.0 \mathrm{~m}$ above the existing ground surface. It can be considered as an average flood scenario and the $F S$ reaches the lowest values. From the results for both boreholes BH-1 and BH-8, liquefaction occurs not only near the surface but either in the depth as shown from the results. The study shows that the liquefaction phenomenon is present and should be taken into consideration in order to avoid any kind of risk. This type of study in a large scale is necessary for all areas with similar geological conditions, which are found along the Albanian coast.

\section{References}

[1] Robertson, P. K., and Wride, C. 1998. "Evaluating Cyclic Liquefaction Potential Using the Cone Penetration Test." Canadian Geotechnical Journal 35: 442-59.

[2] Idriss, I. M., and Boulanger, R. W. 2008. Soil Liquefaction during Earthquake. Oakland: Earthquake Engineering Research Institute.

[3] Moss, R. E. S., Seed, R. B., Kayen, R. E., Stewart, J. P., Der Kiureghian, A., and Cetin, K. O. 2006. "CPT-Based Probabilistic Assessment of Seismic Soil Liquefaction Initiation." Journal of Geotechnical and Geo Environmental Engineering 123 (8): 1032-51.

[4] Juang, C. H., Yuan, H., Lee, D. H., and Ku, C. S. 2002. "Assessing CPT-Based Methods for Liquefaction Evaluation with Emphasis on the Cases from the Chi-Chi, Taiwan." Earthquake, Soil Dynamics and Earthquake Engineering 22: 241-58.

[5] Koçiaj, S., Sulstarova, E., Aliaj, S., Duni, L., Peçi, V., Konomi, N., Dakoli, H., Fuga, I., Goga, K., Zeqo, A., Kapllani, L., Kozmaj, S., and Lika, M. 1985. Seismic Micro-zoning of the City of Vlora. Tirana: Seismological Institute.

[6] Sulstarova, E., Kociaj, S., and Aliaj, S. H. 1980. Seismic Regionalization of PSR of Albania. Tirana: Publication of Academy of Sciences.

[7] Sulstarova, E., Kociaj, S., Muço, B., and Peçi, V. 2003. The Albanian Earthquakes Catalogue for Historical and Instrumental Data with Magnitude Ms $\geq 4$.5. Tirana: Seismological Institute.

[8] Seed, H. B., and Idriss, I. M. 1971. "Simplified Procedures for Evaluating Soil Liquefaction Potential." Journal of Geotechnical and Geo Environmental Engineering 97 (9): 1249-73.

[9] Robertson, P. K. 2010. "Evaluation of Flow Liquefaction and Liquefied Strength Using the Cone Penetration Test." Journal of Geotechnical and Geo Environmental Engineering 136 (6): 842-53.

[10] Liao, S. S. C., and Whitman, R. V. 1986. Catalogue of Liquefaction and Non-liquefaction Occurrences during Earthquakes. Report of Deptpartment of Civil Engineering, Massachusetts Institute Technology, Cambridge.

[11] Robertson, P. K. 2004. "Evaluating Soil Liquefaction and 
Post-earthquake Deformations Using CPT." In Proceeding ISC-2 on Geotechnical and Geophysical Site Characterization, 233-49.

[12] Robertson, P. K. 2010. "Evaluation of Flow Liquefaction and Liquefied Strength Using Cone Penetration Test." Journal of Geotechnical and Geo environmental Engineering 136 (6): 842-53.

[13] Robertson, P. K. 1990. "Soil Classification Using the Cone Penetration Test." Canadian Geotechnical Journal 27 (1): 151-8.
[14] Youd, T. L., and Noble, S. K. 1997. "Magnitude Scaling Factors.' In Proceedings of NCEER (National Center for Earthquake Engineering Research) Workshop on Evaluation of Liquefaction Resistance of Soils, 149-65.

[15] Idriss, I. M. 1990. "Response of Soft Soil Sites during Earthquakes.' In Proceedings of H. Bolton Seed Memorial Symposium, 273-90.

[16] Aliaj, S., Kociaj, S., Muço, B., and Sulstarova, S. 2010. Seismic Regionalization of PSR of Albania. Tirana: Publication of Academy of Sciences. 